\title{
Lung neoplasm mimicking as ectopic pregnancy due to paraneoplastic secretion of human chorionic gonadotropin: a case report and literature review
}

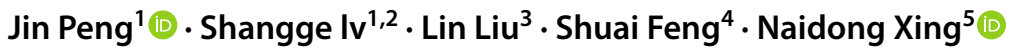

Received: 4 March 2020 / Accepted: 26 November 2020 / Published online: 4 January 2021

(c) The Author(s) 2021

\begin{abstract}
Purpose The present systematic review aimed to examine the relationship between lung neoplasm and human chorionic gonadotropin (HCG). Especially, women with lung neoplasm mimicking as ectopic pregnancy were explored.

Methods A rare case of lung neoplasm with high serum $\beta$-HCG, which was initially thought to be ectopic pregnancy, was reported. A literature search was performed of the US National Library of Medicine (MEDLINE), EMBASE, PubMed, and the Cochrane Database of Systematic Reviews using appropriate keywords and subject headings to February 2020.

Results Studies assessed lung neoplasm patients with positive HCG were included. Twenty studies, including 24 patients, were included. These cases illustrate the importance of considering the possibility of paraneoplastic secretion of $\beta$-HCG in patients who have a positive pregnancy test. This may prevent a delay in the diagnosis and treatment of malignancy in young women. Of the 24 cases, only 7 (29.17\%) were managed surgically; others were managed conservatively or with chemotherapy or radiation.

Conclusion The present systematic review shows the need to re-awaken awareness and high index of suspicion to lung neoplasm diagnosis in patients with positive pregnancy test.
\end{abstract}

Keywords Beta-human chorionic gonadotropin $\cdot \beta-\mathrm{HCG} \cdot$ Lung neoplasm

Naidong Xing

naidongxing@sdu.edu.cn

1 Department of Obstetrics and Gynecology, Qilu Hospital, Shandong University, Jinan 250012, Shandong,

People's Republic of China

2 School of Medicine, Institute of Diagnostics, Shandong University, Jinan 250012, Shandong, People's Republic of China

3 Department of Pathology, Qilu Hospital, Shandong University, Jinan 250012, Shandong, People's Republic of China

4 Shandong Cancer Hospital and Institute, Shandong First Medical University and Shandong Academy of Medical Sciences, Jinan 250117, Shandong, People's Republic of China

5 Department of Urology, Qilu Hospital, Shandong University, Jinan 250012, Shandong, People's Republic of China

\section{Introduction}

Beta-human chorionic gonadotropin ( $\beta$-HCG) belongs to the glycoprotein hormone family and is usually used to exclude pregnancy for patients. Human chorionic gonadotropin (HCG), a 38-kDa glycoprotein hormone, is physiologically produced by syncytiotrophoblast cells in the placenta during pregnancy. It comprises two subunits ( $\alpha$ and $\beta$ polypeptide chains) which are joined by noncovalent bonds. Since the $\alpha$-subunit of HCG has a sequence homology similar to other pituitary hormones, including luteinising hormone (LH), thyroid-stimulating hormone (TSH) and follicle-stimulating hormone (FSH), the $\beta$-subunit of HCG is assayed. HCG is a specific marker for trophoblastic tumors of placenta and gestational tumors [1]. Typically, serum $\beta$-HCG levels are markedly raised in germ cell tumors, particularly pure choriocarcinoma [2]. Ectopic secretion of $\beta$-HCG by other tumors is rare. Ectopic expression of $\beta-\mathrm{HCG}$ was found in epithelial carcinoma, especially for tumors of the stomach, endometrium, ovary, cervix and lung [3-8]. Paraneoplastic syndromes associated with ectopic $\beta$-HCG production have 
been previously described in oropharyngeal squamous cell carcinoma, urothelial carcinoma of bladder, leiomyosarcoma and breast [9-12]. To date, only fewer $\beta$-HCG-secreting lung neoplasm have been reported in the literature. A young woman presenting amenorrhea symptoms with high serum $\beta$-HCG was initially thought to be ectopic pregnancy at our department. Because this case is rare, we here report it and review the literature.

\section{Methods}

A systematic literature search of the US National Library of Medicine (MEDLINE), the Excerpta Medical Database (EMBASE), PubMed, and the Cochrane Database of Systemic Reviews (CDSR) was made using the following search criteria: "lung neoplasm" AND (beta-human chorionic gonadotropin OR HCG). Included data were from the inception of the searched databases until Feb. 2020. The selection process is summarized in Fig. 1. Articles were excluded if they were animal studies, not in the English language, were review articles, were not related to lung neoplasm or did
Fig. 1 Flowchart demonstrating study selection

\section{Studies identified by search strategy $(n=888)$}

\section{Excluded $(n=289)$}

Animal study $(n=19)$

Non-English $(n=205)$

Review article $(n=65)$
Abstracts reviewed for relevance $(n=599)$
Excluded:

Irrelevant $(n=579)$

(Not lung neoplasm)
Studies included

$(n=20)$ 


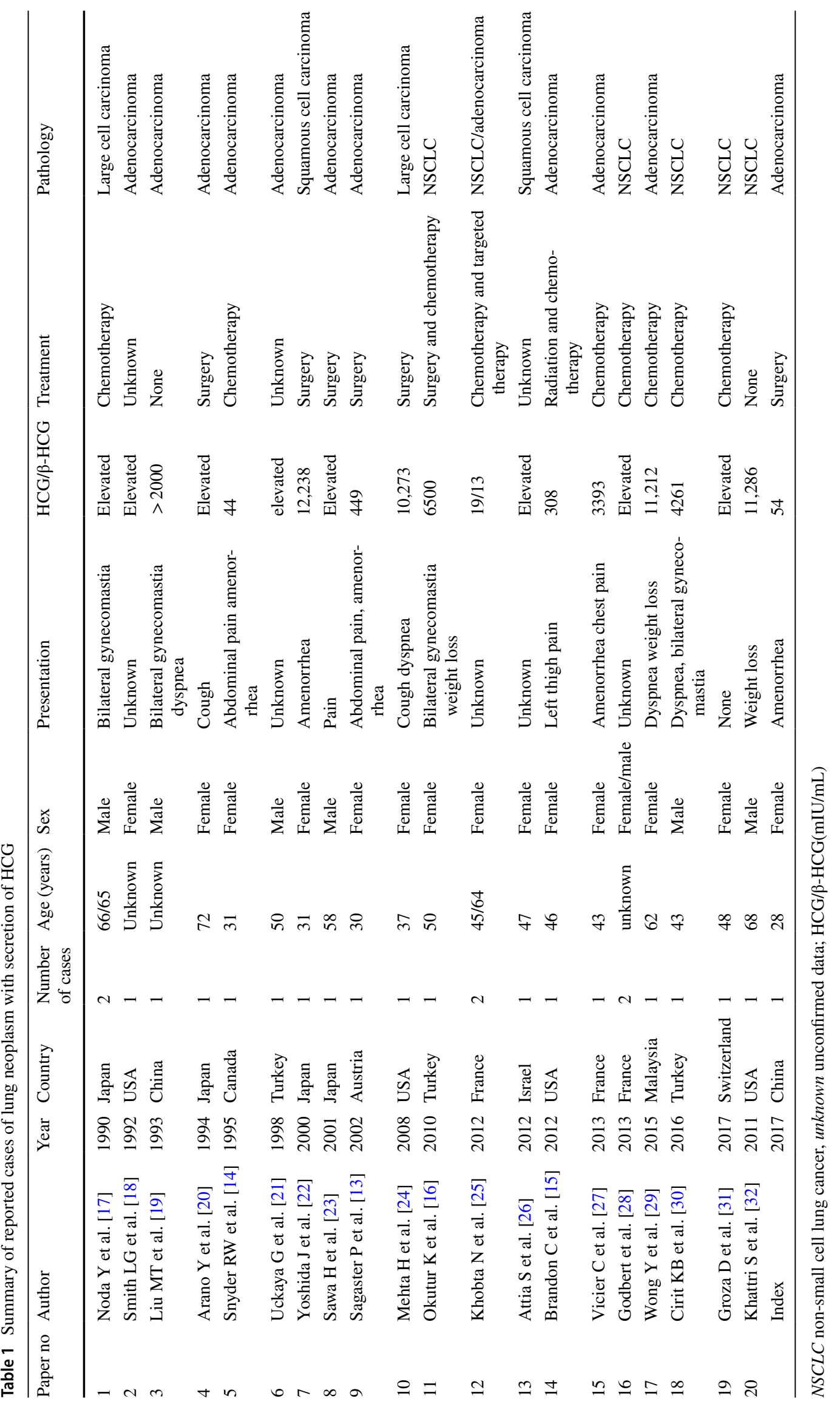


not use either HCG OR beta-human chorionic gonadotropin. Table 1 summarizes the included studies for lung neoplasm and HCG analyzed.

\section{Case report}

A 28-year-old female, a non-smoker, was presenting amenorrhea symptoms, who delivered a baby four years ago and had partial hydatidiform mole history two years ago. Serum $\beta$-HCG levels were found to be high, measuring $54 \mathrm{mIU} / \mathrm{ml}$ (normal upper limit $10 \mathrm{mIU} / \mathrm{ml}$ in nonpregnant woman), which prompted the initial suspicion of pregnancy and further investigations to exclude an ectopic pregnancy or choriocarcinoma. Abdominal and pelvic ultrasonography showed no obvious gestation sac but $1-\mathrm{cm}$ low echo mass. Then, curettage of uterine cavity was performed but no pregnant chorionic villi tissue found by histopathological examination, also $\beta$-HCG elevated as $78 \mathrm{mIU} / \mathrm{ml}$ at 7 th day after curettage. Serum $\beta$-HCG persisted increasingly is $115.3 \mathrm{mIU} / \mathrm{ml}$ at 14 th day after curettage. As suspected diagnosis of ectopic pregnancy, the patient was treated with mifepristone for 3 days and started on chemotherapy with MTX for 7 days. Biochemical response was observed after the first cycle of chemotherapy with downregulation in serum $\beta$-HCG levels from 133.2 to $109.5 \mathrm{mIU} / \mathrm{ml}$. However, Serum $\beta$-HCG is still $119.9 \mathrm{mIU} / \mathrm{ml}$ at 14 th day after chemotherapy (Fig. 2a). Meanwhile, abdominal and pelvic ultrasonography yielded no abnormal findings. Incidentally, X-ray check found a $3-\mathrm{cm}$ round-like high density mass in the left lower lobe lung. Furthermore, a computed tomography (CT) scan of the thorax, abdomen and pelvis following an abnormal chest radiograph disclosed a $3-\mathrm{cm}$ left lower lobe lung mass (Fig. 2b). No other focal lesions were detected. So, a CT-guided biopsy of the left lung mass was subsequently
Fig. 2 a Serum $\beta$-hCG showed before and after the treatment of curettage, chemotherapy and operation. b Computed topography $(\mathrm{CT})$ abdomen and thorax shows a left lower lobe mass (long arrow) which displaces
A
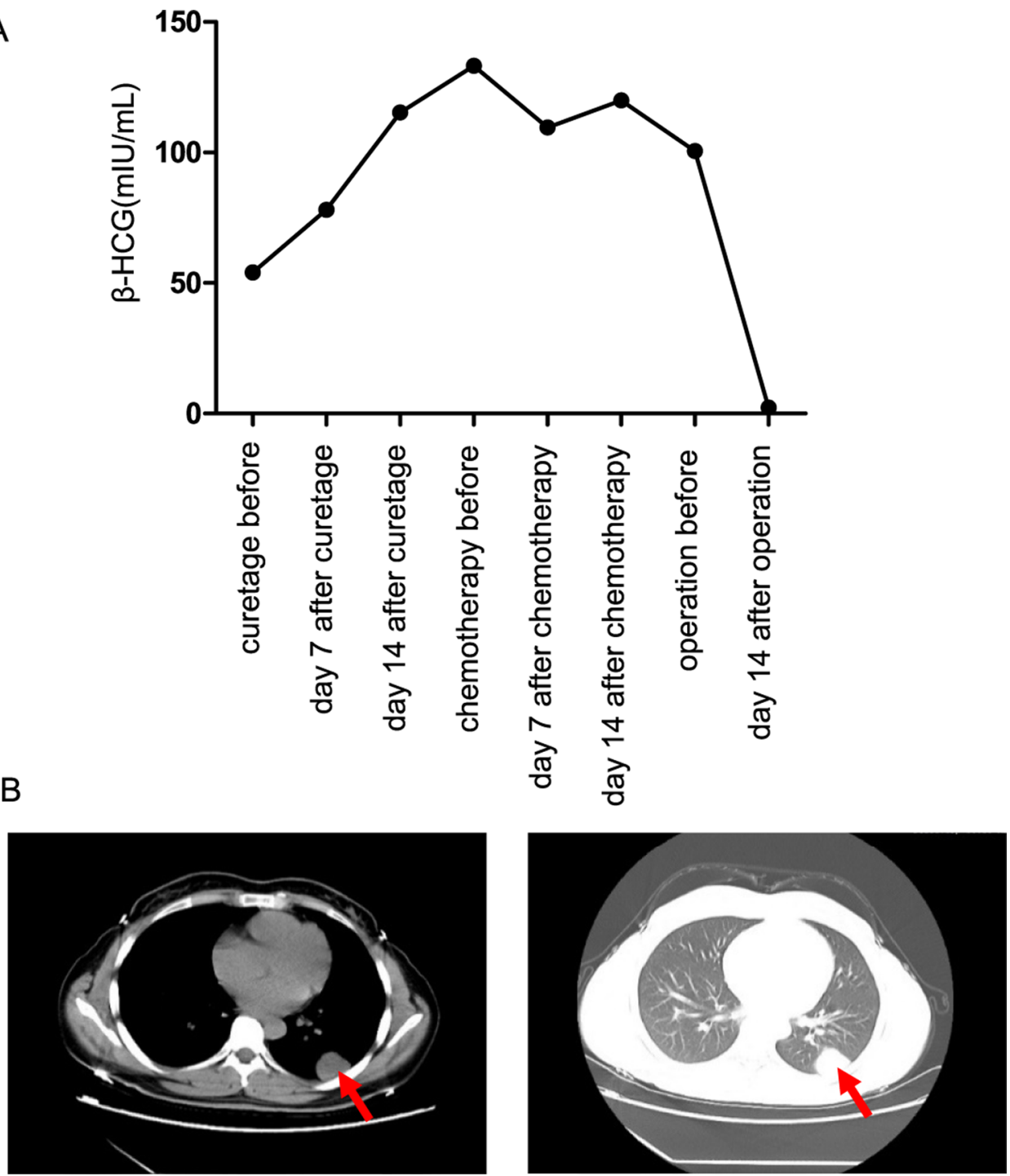
performed. Histopathological examination revealed adenocarcinoma. The malignant cells displayed moderate nuclear pleomorphism, vesicular nuclei with prominent nucleoli and abundant vacuolated to eosinophilic cytoplasm. Atypical mitosis was occasionally encountered (Fig. 3a). There were no multinucleated giant cells, syncytiotrophoblasts and cytotrophoblasts to suggest choriocarcinoma. Immunohistochemically, the malignant cells were diffusely positive for cytokeratin 7 (CK7) and cytokeratin 19 (CK19) (Fig. 3b-c). Other immunomarkers, i.e., cytokeratin 5/6 (CK5/6), TTF-1 and napsin A were negative. $\beta$-HCG is negative, but some of the malignant cells also displayed focal immunopositivity for $\beta$-HCG
(Fig. 3d). A histological diagnosis of $\beta$-HCG-secreting low differentiated adenocarcinoma of the lung was rendered. Then, the patient and family opted for the left lower lobe resection and upper lobe tumor wedge resection. The preoperative and 2-week postoperative HCG levels were 100.5 and $2.3 \mathrm{mIU} / \mathrm{ml}$, respectively (Fig. 2a). So far, the patient has survived more than 28 months after operation.
Fig. 3 Histological and immunohistochemistry features of lung neoplasm; a HE of malignant cells; labelling for $\mathbf{b}$ CK7 and c CK19; d $\beta$-hCG
Fig. 4 The presentation (a) and histological pathology types (b) of reported cases of lung neoplasm with secretion of HCG
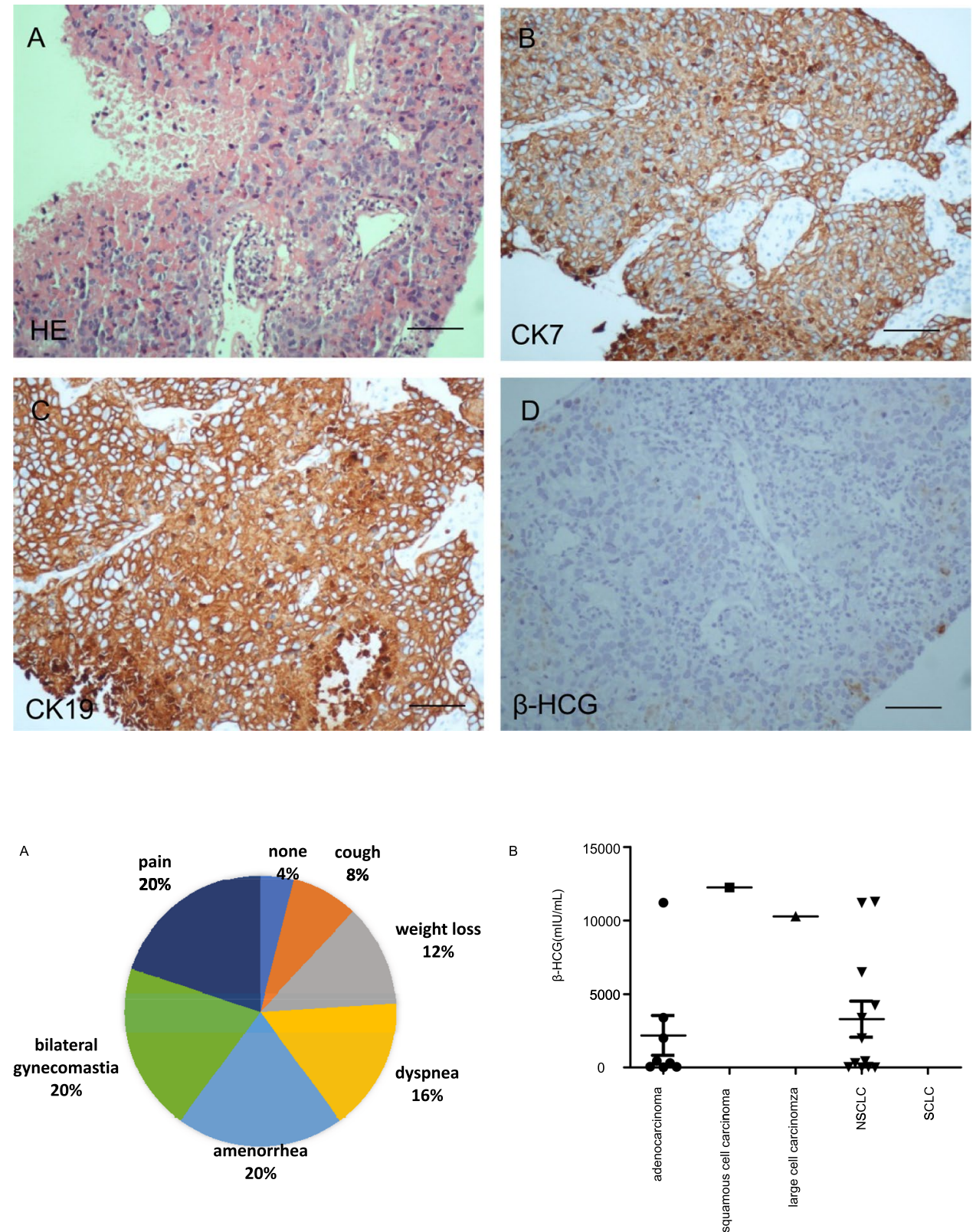


\section{Results}

A total of 24 cases of lung neoplasm with elevated betahuman chorionic gonadotropin including index one were identified (Table 1). Excluding unfirmed data, it consists of 7 male and 17 female patients with elevated mean level of $\mathrm{HCG}$ which is $6703 \mathrm{mIU} / \mathrm{mL}$. Mean age of these cases is 49.8 years. The presentation of 24 patients shows diversity, $8 \%$ cough, $20 \%$ pain, $12 \%$ weight loss, $16 \%$ dyspnea and $40 \%$ ectopic pregnancy-related symptoms $(20 \%$ amenorrhea and $20 \%$ bilateral gynecomastia), while $4 \%$ patients have no presentation (Fig. 4a). Only 7 patients of them have chance to receive operation and 14 patients received chemotherapy and/or radiation and/or targeted therapy. 2 patients died soon after diagnosis who do not receive treatment and 2 cases revealed without treatment data. The histological type of these cases is 7 non-small cell lung cancer (NSCLC), 2 squamous cell carcinomas, 12 adenocarcinoma and 3 large cell lung cancer (Fig. 4b). Interestingly, we did not find the histological type of small cell lung cancer (SCLC) case. The elevated mean HCG level of adenocarcinoma and NSCLS is $2184 \mathrm{mIU} / \mathrm{mL}$ and $5516 \mathrm{mIU} / \mathrm{mL}$, respectively.

\section{Discussion}

We report a case of a young female patient who presented with amenorrhea symptoms and was found to have a positive pregnancy test. Subsequently, she was found to have lung adenocarcinoma with ectopic $\beta$-HCG secretion. Ectopic production of a variety of hormones such as $\mathrm{ADH}$, parathyroid hormone, ACTH, insulin-like growth factor, thus leading to presentation as endocrine syndromes in patients with lung cancer are well known. Little is known about paraneoplastic secretion of $\beta$-HCG. Expression of ectopic $\beta$-HCG is not associated with any specific histological subtypes, although some authors have found that this phenomenon is more common in lung adenocarcinoma. Interestingly, according to reported cases, we observed diverse histological pathology cases excluding small cell lung cancer (SCLC), maybe due to limited cases. As the same as most reported cases of $\beta$-HCG-secreting lung adenocarcinoma, our report shows that serum $\beta$-HCG levels of adenocarcinoma is $2184 \mathrm{mIU} /$ $\mathrm{mL}$. Although no studies showed $\beta$-HCG levels appropriate as a diagnostic marker for lung cancer, future studies may benefit from large sample study to assess the comprehensive paraneoplastic $\beta$-HCG production by lung carcinoma of various histological types.

The precise mechanism of $\beta$-HCG secreted by non-trophoblastic tumors is poorly understood. The ectopic production of trophoblastic hormones by lung carcinoma has not been investigated systemically. Recent findings suggest that glycoprotein- and protein hormones act as local paracrine growth in normal and malignant tissues. Besides their important biological role in promoting progesterone production in the uterine vasculature during pregnancy, free $\beta$-HCG was recently found to play a major role in the tumorigenesis of non-trophoblastic tumors [13]. They acted as an autocrine anti-apoptotic and angiogenic growth factor, resulting in cancer cell growth. This may also explain the chemoresistance and aggressiveness of $\beta$-HCG-secreting lung cancer. Some authors have shown a high expression of $\beta$-HCG in metastatic lung cancer cell lines, which may attribute to the metastatic potential of such secreting tumors [14]. The findings supported the potential use of serum $\beta$-HCG to predict patients who were at risk of developing metastatic disease. In our case, immunohistochemistry analysis of lung adenocarcinoma revealed negative staining of cancer cells, since serum $\beta$-HCG was low, maybe due to early stage of lung cancer.

At present, no chemotherapy regimen is available for such rare tumors. Interestingly, slight reduction of serum $\beta$-HCG level was observed after chemotherapy. Serial measurements of circulating $\beta$-HCG seemed to be influenced by anti-neoplastic treatments. The serum $\beta$-HCG level returned to normal 2 weeks after the operation.

Lung cancer mortality is strongly associated with the predominant diagnosis of late stage lesions that hampers effective therapy [15]. The level of $\beta$-HCG measured in tumor tissues in NSCLC patients was not of prognostic, diagnostic or predictive significance for OS or recurrence after treatment [16]. We identified that the mean age at diagnosis for $\beta$-HCG-secreting lung neoplasm was 50 years old, which was much older than the usual age for pregnancy-related disease. Otherwise, our case is 28 years old. We omit X-ray or CT examination of chest. So that our case was misdiagnosed at first. We here firstly revealed that $\beta$-HCG-secreting lung neoplasm presented with $40 \%$ ectopic pregnancy-related symptoms (20\% amenorrhea and $20 \%$ bilateral gynecomastia), which was easily confused with extrauterine pregnancy clinically. Only $29.17 \%$ ( 7 out of 24 cases) had chance to receive operation, maybe due to delay diagnosis. Fortunately, our case could be operated on for lung cancer immediately. Thus, here we emphasize the need to aware of such young women cases with elevated HCG which is related not only with pregnancy-related disease, but also the lung cancer. 


\section{Conclusion}

In conclusion, the present systematic review shows that $\beta$-HCG-secreting lung neoplasm is easily confused with extrauterine pregnancy clinically. Therefore, knowing the expression of $\beta$-HCG by lung tumors may facilitate prompt diagnosis and initiation of appropriate intervention in time. This review examines the literature regarding a known indicator $\beta$-HCG of lung cancer, maybe it is the first step in exploring further research about the role of $\beta$-HCG in lung neoplasm.

Author contribution JP: involved in the drafting of articles and data analysis. SF: participate in revising the manuscript. SL: participate in surgery. LL: data collections. NX: study design and data analysis.

Funding This work was partially supported by grants from the Department of Medical and Health Science Technology of Shandong province [Project Nos. 2016WS0345], and from the National Natural Science Foundation of China [Nos. 81602286], and Department of Science Technology of Jinan city [project Nos. 201705051], and China Postdoctoral Science Foundation [Nos. 2019T120594], and Shandong natural science united foundation for cancer control [Nos. ZR2019LZL002].

\section{Compliance with ethical standards}

Conflict of interest We declare that we have no conflict of interest.

Ethical approval The study was approved by the Research Committee of the Qilu Hospital of Shandong University, Ji'nan, Shandong, China.

Open Access This article is licensed under a Creative Commons Attribution 4.0 International License, which permits use, sharing, adaptation, distribution and reproduction in any medium or format, as long as you give appropriate credit to the original author(s) and the source, provide a link to the Creative Commons licence, and indicate if changes were made. The images or other third party material in this article are included in the article's Creative Commons licence, unless indicated otherwise in a credit line to the material. If material is not included in the article's Creative Commons licence and your intended use is not permitted by statutory regulation or exceeds the permitted use, you will need to obtain permission directly from the copyright holder. To view a copy of this licence, visit http://creativecommons.org/licenses/by/4.0/.

\section{References}

1. Ben KW, Ben HR, Charfi S et al (2018) Gastric signet-ring cell carcinoma with hypersecretion of $\beta$-Human chorionic gonadotropin and review of the literature. Exp Oncol 40(2):149-151

2. Marshall C, Enzerra M, Rahnemai-Azar AA, Ramaiya NH (2019) Serum tumor markers and testicular germ cell tumors: a primer for radiologists. Abdom Radiol (NY) 44(3):1083-1090

3. Bozdag Z, Taslar AM, Tepe NB, Dizibuyuk OF, Ozcan HC, Karakök M (2018) The re-awakening of hCG expression. Its role in the diagnosis of cervical squamous cell carcinoma. Saudi Med J 39(9):873-877

4. Cai H, Zhou R, Liang W, Wang J (2018) Dedifferentiated endometrioid adenocarcinoma with trophoblastic components and elevated serum alfa-fetoprotein: a case report and literature review. Medicine (Baltimore) 97(17):e0551

5. Heidegger H, Jeschke U (2018) Human chorionic gonadotropin (hCG) - an endocrine, regulator of gestation and cancer. Int J Mol Sci 19(5): 1502

6. Yadav S, Sagar N, Mallya V, Mandal S, Khurana N, Gupta S (2018) Extensive trophoblastic differentiation in case of an endometrial carcinoma. Indian J Pathol Microbiol 61(4):614-616

7. Zhao R, Zhang T, Xi W et al (2018) Human chorionic gonadotropin promotes cell proliferation through the activation of c-Met in gastric cancer cells. Oncol Lett 16(4):4271-4278

8. Wu W, Gao H, Li X et al (2019) $\beta$-hCG promotes epithelial ovarian cancer metastasis through ERK/MMP2 signaling pathway. Cell Cycle 18(1):46-59

9. Gu H, Sui S, Cui X et al (2018) Thyroid carcinoma producing $\beta$-human chorionic gonadotropin shows different clinical behavior. Pathol Int 68(4):207-213

10. Kölbl AC, Schlenk K, Behrendt N, Andergassen U (2018) The importance of hCG in human endometrial adenocarcinoma and breast cancer. Int J Biol Markers 33(1):33-39

11. Daskalakis K, Chatzelis E, Tsoli M et al (2019) Endocrine paraneoplastic syndromes in patients with neuroendocrine neoplasms. Endocrine 64(2):384-392

12. Nicholson BD, Jones NR, Protheroe A et al (2019) The diagnostic performance of current tumour markers in surveillance for recurrent testicular cancer: a diagnostic test accuracy systematic review. Cancer Epidemiol 59:15-21

13. Sagaster P, Zojer N, Dekan G, Ludwig H (2002) A paraneoplastic syndrome mimicking extrauterine pregnancy. Ann Oncol 13(1):170-172

14. Manzi D, Greenberg B, Maier D, Forouhar F, Malchoff CD (1995) Bronchogenic carcinoma presenting as a pseudopregnancy. Chest 107(2):567-569

15. Maughan BC, Kamat A (2012) Lung carcinoma presenting with pathologic femur fracture and false-positive pregnancy test result. Ann Emerg Med 60(3):378-380

16. Okutur K, Hasbal B, Aydin K et al (2010) Pleomorphic carcinoma of the lung with high serum beta-human chorionic gonadotropin level and gynecomastia. J Korean Med Sci 25(12):1805-1808

17. Noda Y, Simodaira M, Ito H et al (1990) Two cases of human chorionic gonadotropin-producing large cell carcinoma of the lung accompanied with gynecomastia. Nihon Kyobu Shikkan Gakkai Zasshi 28(5):781-785

18. Smith LG, Lyubsky SL, Carlson HE (1992) Postmenopausal uterine bleeding due to estrogen production by gonadotropin-secreting lung tumors. Am J Med 92(3):327-330

19. Liu MT (1993) Bronchogenic carcinoma accompanied with gynecomastia. A case report. Zhonghua Jie He He Hu Xi Za Zhi 16(2): $101-2,125$

20. Arano Y, Shimizu J, Murakami S et al (1994) A female case of adenocarcinoma of the lung producing human chorionic gonadotropin. Kyobu Geka 47(6):485-487

21. Uçkaya G, Ozet A, Arpaci A, Kömürcü S (1998) Human chorionic gonadotropin and CA $15-3$ producing adenocarcinoma. Nuklearmedizin 37(8):297-298

22. Yoshida J, Nagai K, Nishimura M et al (2000) Secretion of hCG/ beta-hCG by squamous cell carcinoma of the lung in a 31-year-old female smoker. Jpn J Clin Oncol 30(3):163-166

23. Sawa H, Taomoto K, Tamaki N, Obayashi C, Nishimura R (2001) Metastatic bronchogenic carcinoma with human chorionic gonadotropin production manifesting as cerebellar hemorrhage-case report. Neurol Med Chir (Tokyo) 41(8):406-410

24. Mehta H, Bahuva R, Sadikot RT (2008) Lung cancer mimicking as pregnancy with pneumonia. Lung Cancer 61(3):416-419

25. Khobta N, Tomasini P, Garcia ME, Garcia S, Barlesi F (2012) $\beta$-Human chorionic gonadotropin (HCG) dosage and lung cancer: 
a pitfall when screening patients for clinical trials. Bull Cancer 99(11):1065-1068

26. Attia S, Ben-Nun A, Rabin T, Peled N (2012) Ectopic pregnancy as a presenting symptom for lung cancer. Harefuah 151(7): 398401, 436

27. Vicier C, Tabouret E, Tallet A et al (2013) BetaHCG secretion by a pulmonary adenocarcinoma. World J Surg Oncol 11:228

28. Godbert B, Tiotiu A, Masias C, Martinet Y (2013) Inadequate secretion of $\beta$-human chorionic gonadotropin in lung cancer. Rev Pneumol Clin 69(5):298-301

29. Wong YP, Tan GC, Aziz S, Pongprakyun S, Ismail F (2015) Betahuman chorionic gonadotropin-secreting lung adenocarcinoma. Malays J Med Sci 22(4):76-80

30. Cirit KB, Erdoğan Y, Akıncı ÖB, Büyükyaylacı ÖS, Demirağ F (2016) $\beta$-HCG secretion by a non-small cell lung cancer: a case report. Tuberk Toraks 64(1):69-72
31. Groza D, Duerr D, Schmid M, Boesch B (2017) When cancer patients suddenly have a positive pregnancy test. BMJ Case Rep. 2017

32. Khattri S, Vivekanandarajah A, Varma S, Kong F (2011) Secretion of beta-human chorionic gonadotropin by non-small cell lung cancer: a case report. J Med Case Rep 5:19

Publisher's Note Springer Nature remains neutral with regard to jurisdictional claims in published maps and institutional affiliations. 